\title{
Biocontrol Potential of Metarhizium anisopliae (Metsch.) Sorokin (Deuteromycotina: Hyphomycetes) against Ailanthus Defoliator, Eligma narcissus (Cram.)
}

\author{
N.S. Bai ${ }^{1 *}$, T.O. Sasidharan ${ }^{1}$, O.K. Remadevi ${ }^{2}$ and P. Dharmarajan ${ }^{1}$ \\ ${ }^{1}$ Ashoka Trust for Research in Ecology and the Environment, Royal Enclave, \\ Bengaluru, India \\ ${ }^{2}$ Institute of Wood Science and Technology, Malleswaram, Bengaluru. India
}

Date Received: 04-01-2015 Date Accepted: 11-05-2015

\begin{abstract}
Eligma narcissus is recognised as a serious pest of Ailanthus in Southern India and defoliation of Ailanthus by this pest causes apparent loss of growth increment. The common control methods for this pest is mostly insecticides and the concern about the environmental effects of chemical insecticides, has emphasised the use of environmentally more benign microbial agents. Among entomopathogens, Fungi are the most explored and often act as important natural control agents that limit insect populations. On this point of view, Bio efficacy of 25 isolates of Metarhizium anisopliae was assessed to establish their virulence against $E$. narcissus in the laboratory and effective formulations of two potent isolates were subsequently evaluated in the field. MIS7 and MIS13 were more effective among the different isolates evaluated against $E$. narcissus. The median lethal concentration $\left(\mathrm{LC}_{50}\right)$ of all the isolates ranged from $6.46 \times 10^{5}$ conidia/ml to $628.92 \times 10^{5}$ conidia $/ \mathrm{ml}$. Median lethal concentration of $\left(\mathrm{LT}_{50}\right)$ of 4.9 and 5.4 days were recorded for MIS7 and MIS13 respectively at a concentration of $1 \times 10^{7}$ conidia/ml. Virulence tests of the isolates MIS7 and MIS13 and 0.5\% Pongamia pinnata seed oil, individually and in different combinations, indicated improved efficacy of the isolates when used in combination and also when combined with seed oil. Formulations composed of "MIS7+MIS13+0.5\% Pongamia pinnata seed oil" and "MIS7+MIS13" proved to be superior against E. narcissus, causing $76.30 \%$ and $93.93 \%$ mortality, respectively. Field evaluation of the formulation MIS7+MIS13+0.5\% Pongamia pinnata seed oil recorded 5.79 larvae per plant resulting in $60.53 \%$ reduction of infestation while the formulation, MIS7+MIS13 showed 53.76\% reduction of infestation with 6.56 larvae per plant. The observations from this study suggest the prospects of using the entomopathogenic fungus, $M$. anisopliae for the control of E. narcissus.
\end{abstract}

Keywords: Ailanthus, defoliation, Eligma narcissus, Metarhizium anisopliae, biocontrol

\section{Introduction}

Ailanthus excelsa Roxb. is a genus of trees belonging to the family Simaroubaceae. It is one of the promising fast growing multipurpose tree species in India (Tewari, 1992). Like any other forest tree,

\footnotetext{
*Correspondence: sapnabai@gmail.com

Tel: +4919746548242

ISSN 2235-9370 Print/ISSN 2235-9362 Online (C University of Sri Jayewardenepura
} 
Ailanthus is also submitted to the attacks of insect pests. Bhasin and Roonwal (1954) reported 17 insects associated with Ailanthus belonging to 5 orders such as Coleoptera, Lepidoptera, Hemiptera, Thysanoptera and Isoptera. Among the various pest species, Eligma narcissus is recognised as a serious pest of Ailanthus in Southern India (Chatterjee and Sen Sarma, 1968). It is distributed all over India and feeds on almost all species of Ailanthus. Several species have been recognised and the one that occurs in India has been identified as E. narcissus (Roonwal, 1982). It does not show any clear seasonal trend in occurrence. Pest build up is generally on increase during September-January (Varma, 1986, 1991). Jha and Sen Sarma, (2008) opined that the occurrence of the pest is unpredictable and generally no association is observed with rainfall and the incidence followed a clustered pattern each time the density of the population increased. They feed on young as well as mature leaves. About 20-40 larvae feed voraciously on each leaf at times of heavy defoliation. Pest incidence in older plantations is rare compared to young plantations (David and Ananthakrishnan, 2004). Usually saplings up to five years old are infected and mature trees are free from attack. Larvae are reported to feed on green parts of the stem when all the leaves are consumed. Defoliation by this pest causes apparent loss of growth increment (Varma, 1986; Nair, 2007).The common control methods reported for this pest is by using chemicals, mostly insecticides although a few bacterial pathogens and plant extracts are tried. In recent times there has been growing public concern about the environmental effects of synthetic chemical insecticides, which has led to increased use of specific, environmentally more benign microbial agents (Cunningham and Frankenhuyzen, 1991).

Biological control involves employment of natural enemies such as predators, parasitoids, pathogens or competitors of a pest to help keep its numbers in check. In general the pathogens function naturally in the environment as population suppressors (Saxena, 2008). Fungi are the maximum explored organisms among entomopathogens and often act as important natural control agents that limit insect populations (Weinzierl and Henn, 1991). M. anisopliae is a recognised pathogen of more than 200 insect species, including several major pests. Metarhizium has been developed into commercial products for use in several countries (Kabuluk et al., 2001). While the products of this fungus have found major use in many developed countries, the efforts on these lines are yet to get popularized in India. Hitherto, there are no reports of any study on efficacy of Metarhizium fungi against $E$. narcissus in India. In view of this, the present investigation was undertaken to evaluate the potential of various isolates of $M$. anisopliae for controlling E. narcissus. Bioefficacy of 25 isolates of $M$. anisopliae was assessed for their virulence against $E$. narcissus with the objective of identifying potential strains. Two most promising isolates and Pongamia pinnata seed oil were evaluated individually and in different combinations in the laboratory and the effective formulations were tested in the field.

\section{Methodology}

\subsection{Insect culture}

Healthy larvae of E. narcissus (Figure 1) collected from field were reared in the laboratory and allowed to pupate and develop into adults. Male and female moths were released into glass bottles covered with muslin cloth. Diluted sucrose (10\%) was provided on cotton balls as food. The muslin cloths with eggs were surface sterilized with $1 \%$ sodium hypochlorite for $15 \mathrm{~min}$ and dipped in sterile distilled water for $10 \mathrm{~min}$ and placed over a blotting paper for drying. It was then covered with tender Ailanthus leaves and transferred to glass bottles for hatching. The larvae initially established on tender leaves were transferred with fine camel hair brush to plastic boxes (14 cm diameter, $6 \mathrm{~cm}$ height) with fresh Ailanthus leaves. The petiole of the leaves were wrapped in a layer of moist tissue paper and sealed with parafilm to prevent wilting. Every two days, fresh leaves were provided. The pupae were 
removed from the rearing containers within 24 hours of pupation and transferred to rearing cages for emergence.

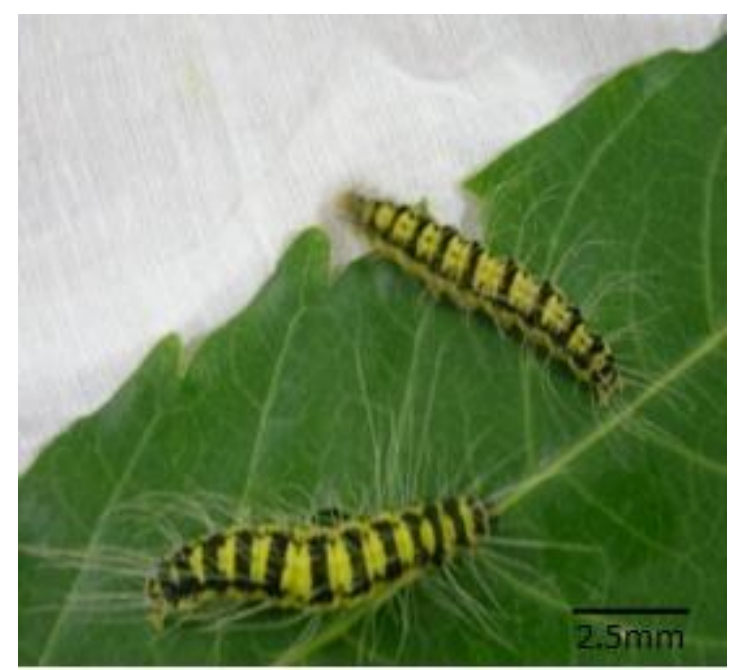

Figure 1: Healthy larva of E. Narcissus.

\subsection{Fungus}

Among the 25 fungal isolates used in this study, 16 were collected from field and nine received from different institutions. The isolates from field were recovered and purified from soil and insects. Soil samples were collected up to a depth of $30 \mathrm{~cm}$ from different study areas. Galleria bait method was used to isolate the fungus from soil samples. After removing roots and gravel, soil samples were sifted through a $5 \mathrm{~mm}$ sieve. Thereafter, plastic boxes $(10 \mathrm{~cm}$ high, $8 \mathrm{~cm}$ diameter) were filled with $100 \mathrm{~g}$ of soil and ten Galleria mellonella late instar larvae were introduced. The lids were punched for making air holes. The larvae were incubated at $20^{\circ} \mathrm{C}$ in dark conditions.

During the first five days, the boxes were turned once daily to make bait insects penetrate as much soil as possible. After 7-10 days, boxes were examined every other day and dead larvae were collected. Cadavers thus obtained and those collected from field were surface-sterilised by dipping sequentially in $70 \%$ ethyl alcohol, $1 \%$ sodium hypochlorite, and sterile distilled water; each for 3 min. The larvae were dissected and placed on PDA/Veen's medium and incubated at $28 \pm 1{ }^{\circ} \mathrm{C}$ and $90 \% \mathrm{RH}$ to facilitate growth and sporulation of the fungus. Slant cultures were prepared from a single colony and stored at $-20^{\circ} \mathrm{C}$. The viability and virulence of the cultures were maintained by sub culturing and passage through the host at regular intervals (Zimmermann, 1986; Zayed, 2003).

\subsection{Pathogenicity studies}

Inoculum preparation

Metarhizium spores were harvested from PDAY plate culture by flooding with $10 \mathrm{ml}$ of $0.05 \%$ Tween 80 in sterile distilled water and dislodging the conidia into suspension with a glass rod. The suspension was filtered through a double layered sterile cheese cloth and centrifuged at 1,700 rpm for $15 \mathrm{~min}$. The supernatant was discarded and the conidia re-suspended in $5 \mathrm{ml}$ sterile distilled water. This stock spore suspension was stored at $4{ }^{\circ} \mathrm{C}$ for $24 \mathrm{~h}$ until spore viability was determined. Only cultures with $>90 \%$ viability were used. Counts of conidia were made from the stock suspension using an improved Neubauer haemocytometer. Spore suspensions containing $1 \times 10^{3}, 1 \times 10^{4}, 1 \times 10^{5}, 1 \times 10^{6}$, 
$1 \times 10^{7}$ and $1 \times 10^{8}$ conidia/ml sterile distilled water with $0.05 \%$ Tween 80 were prepared from the stock for bioassay.

\section{Bioassay}

Bioassay of all the 25 isolates was carried out against the selected pests using inoculum concentrations ranging from $10^{3}-10^{8}$ conidia/ml to determine the multiple dose-mortality $\left(\mathrm{LC}_{50}\right)$ and Time-dose-mortality $\left(\mathrm{LT}_{50}\right)$ responses. Ten second instar pest larvae were placed separately in sterile 20 $\mathrm{ml}$ vials and $10 \mathrm{ml}$ of fungal suspension was added. The vials were capped and inverted five times over a $5 \mathrm{~s}$ period, to ensure that the insects were completely drenched. For the controls, insects were treated with $0.05 \%$ Tween 80 in the same manner. Treated and untreated (control) E. narcissus were transferred with fine camel hair brush into separate plastic boxes $(14 \mathrm{~cm}$ diameter, $6 \mathrm{~cm}$ height $)$ with fresh Ailanthus leaves as food source. The petiole of the leaves were wrapped in a layer of moist tissue paper and sealed with parafilm to prevent wilting. The boxes were incubated at $26 \pm 1{ }^{\circ} \mathrm{C}, 90 \% \mathrm{RH}$, 12:12 (L:D). Once in two days, the leaves were replaced with fresh leaves. Each concentration of a single isolate was replicated four times. Mortality of larvae was recorded every $24 \mathrm{~h}$ for eight days after exposure. Dead larvae were counted and removed each day to prevent horizontal contamination. The dead larvae from each treatment were incubated in moist conditions to determine if death resulted from mycosis. Symptoms of mycosis in cadavers included distension and rigidity, a mottled rusty brown coloring, and development of $M$. anisopliae hyphae on the exterior of the integument (Figure 2).

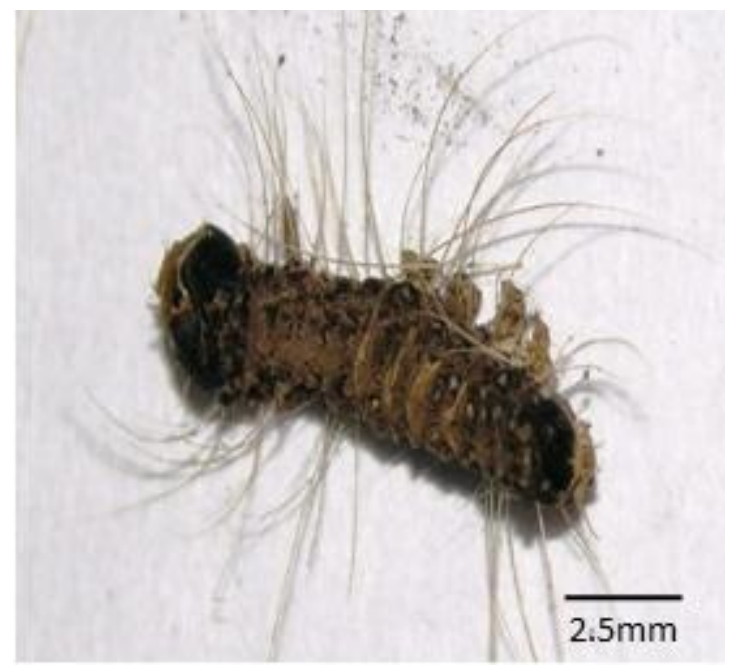

Figure 2: Mycosed cadavers of E. Narcissus.

The efficacy of two most promising isolates, MIS7 $\left(10^{7}\right.$ conidia/ml) and MIS13 (10 ${ }^{7}$ conidia/ml), and $0.5 \%$ P. pinnata seed oil was further evaluated individually and in different combinations as per the above method to determine the synergistic effect of combinations on the mortality of E. narcissus.

\section{Field trial}

Two formulations of each of the isolates, MIS7 and MIS13, which proved promising in the laboratory, were evaluated in Ailanthus plantations at two locations of Odagathur forest division in the Vellore district of Tamil Nadu where peak pest attack was observed. Different treatments viz., water formulation of conidia: T1 (MIS7 and MIS13 at a concentration of $10^{14}$ conidia/ml $0.08 \%$ Tween 80 ), Oil formulation of conidia:T2 (MIS7 and MIS13 at $10^{14}$ conidia/ml of $0.08 \%$ Tween 80 with $0.5 \% P$. 
pinnata seed oil) along with control T3 (0.08\% Tween 80) were field evaluated in four year old Ailanthus plantation infested by E. narcissus. Germination test of the formulations was done one day prior to application and was found to be over $80 \%$. The field layout was in a Randomised Block Design (RBD) consisting of three treatments (two treatments and control) in a plot of size $82 \times 46 \mathrm{~m}^{2}$ with each treatment replicated four times. The subplots measuring $22 \times 12 \mathrm{~m}^{2}$ in each replication had seven rows (ten plants each), $2 \mathrm{~m}$ apart (five main rows and two skip rows, one on either side of main rows). Each subplot was separated from the other by two skip rows $2 \mathrm{~m}$ apart (one row from each subplot). The population counts of E. narcissus were recorded a day before the imposition of treatments.

The total numbers of larvae on all the leaves of ten randomly selected tagged plants in each plot were recorded. The treatments were imposed using power sprayer. Post treatment observations on the number of larvae were recorded at seven and fifteen days after the spray. For each treatment, the averages of all the observations from two locations were used to determine the average percent reduction of pest population calculated using Henderson and Tilton equation (Henderson and Tilton, 1955).

\subsection{Statistical Analysis}

Median lethal concentration $\left(\mathrm{LC}_{50}\right)$ and median lethal time $\left(\mathrm{LT}_{50}\right)$ values were calculated using probit analysis (Finney, 1971). Field trial data were subjected to analysis of variance (ANOVA).

\section{Results}

\subsection{Bioassay}

MIS7, MIS13, MIS2 and MIS20 were more effective among the different isolates evaluated against $E$. narcissus. The $\mathrm{LC}_{50}$ values of all the isolates ranged from $6.46 \times 10^{5}$ conidia/ml to $628.92 \times 10^{5}$ conidia/ml. The least $\mathrm{LC}_{50}$ value of $6.46 \times 10^{5}$ conidia $/ \mathrm{ml}$ was exhibited by isolate MIS7, followed by MIS13 (14.48 $\times 10^{5}$ conidia/ml) (Table 1). The LT $_{50}$ values were 4.9, 5.7, 6.8 and 7 days for MIS7 at $1 \times 10^{7}, 1 \times 10^{6}, 1 \times 10^{5}$ and $1 \times 10^{4}$ conidia/ml respectively and 5.4, 6.1, 6.8 and 7.1 days for MIS13 (Table 2). The least $\mathrm{LC}_{50}$ and $\mathrm{LT}_{50}$ values of MIS7 proved it to be the most effective isolate against $E$. narcissus followed by MIS13. Hitherto there are no reports of any study on efficacy of Metarhizium fungi against $E$. narcissus in India. The present study assumes significance in this context. Chatterjee et al. (1969) reported the ability of entomopathogenic fungi, Beauveria bassiana to cause white muscardine disease on E. narcissus. Paecilomyces farinosus was isolated from naturally infected pupae of E. narcissus. Mortality of E. narcissus larvae within 48-72 h of incubation and 40\% pupal mortality were reported due to $P$. farinosus (Mohanan and Varma, 1988).

$P$. fumosoroseus was also recognised to be effective in controlling larvae and pupae of $E$. narcissus (David and Ananthakrishnan, 2004). Laboratory studies by releasing E. narcissus larvae on host plant leaves treated with $P$. farinosus spores showed mortality within $72 \mathrm{~h}$ which ranged from $77 \%$ for late instar larvae to $90 \%$ for early instars. Some of the inoculated larvae which could pupate, failed to emerge and even when emerged died in few hours (Mohammed Ali and Varma, 1992; Mohammed Ali et al., 1991). Varma and Mohammed Ali (1986) isolated a bacterial pathogen, Bacillus firmus from field population of E. narcissus and confirmed their pathogenicity with $80-100 \%$ mortality in larvae within 18-24 $\mathrm{h}$ under laboratory conditions. The antifeedant and growth inhibitory effects of methanolic extract of neem seed kernel (NSKE) was evaluated against final instar larvae of $E$. narcissus which pointed out the feeding deterrence and growth inhibition of the treated larva in a dosedependent manner (Joseph, 2000). 
Table 1: Dose-mortality response $\left(\mathrm{LC}_{50}\right)$ of Metarhizium isolates to E. narcissus.

\begin{tabular}{|c|c|c|c|c|c|c|c|}
\hline \multirow[t]{2}{*}{ Rank } & \multirow[t]{2}{*}{ Isolates } & \multirow[t]{2}{*}{$\mathrm{LC}_{50}\left(\times 10^{5}\right)$} & \multicolumn{2}{|c|}{ Fiducial Limits } & \multirow[t]{2}{*}{ Slope \pm SE } & \multirow[t]{2}{*}{$\chi^{2}$} & \multirow[t]{2}{*}{$\mathrm{P}$} \\
\hline & & & Lower $\left(\times 10^{5}\right)$ & $\operatorname{Upper}\left(\times 10^{5}\right)$ & & & \\
\hline 1 & MIS7 & 6.46 & 1.37450 & 57.47463 & $2.6 \pm 0.7$ & 0.027 & 0.986 \\
\hline 2 & MIS13 & 14.48 & 2.29119 & 1562.76166 & $2.2 \pm 0.7$ & 0.124 & 0.940 \\
\hline 3 & MIS2 & 17.87 & 4.41148 & 267.80663 & $3.0 \pm 0.8$ & 0.082 & 0.960 \\
\hline 4 & MIS20 & 37.35 & 8.76363 & 1164.59796 & $3.2 \pm 0.8$ & 0.448 & 0.799 \\
\hline 5 & MIS1 & 62.61 & 13.85899 & 3275.18707 & $3.3 \pm 0.8$ & 0.264 & 0.876 \\
\hline 6 & MIS3 & 110.02 & 12.70988 & 56424919.74126 & $2.3 \pm 0.7$ & 0.018 & 0.991 \\
\hline 7 & MIS19 & 116.42 & 14.60324 & 4672517.23670 & $2.5 \pm 0.8$ & 0.139 & 0.933 \\
\hline 8 & MIS15 & 123.14 & 33.27831 & 3809.16306 & $4.8 \pm 1.2$ & 0.612 & 0.736 \\
\hline 9 & MIS23 & 156.12 & 22.38051 & 656584.13095 & $2.9 \pm 0.8$ & 0.320 & 0.852 \\
\hline 10 & MIS18 & 157.60 & 20.04840 & 3631025.35580 & $2.7 \pm 0.8$ & 0.118 & 0.943 \\
\hline 11 & MIS4 & 178.96 & 63.58669 & $2.458914 \mathrm{E}+49$ & $2.5 \pm 0.8$ & 0.019 & 0.990 \\
\hline 12 & MIS10 & 192.66 & 31.65834 & 127503.57566 & $3.5 \pm 0.9$ & 0.087 & 0.958 \\
\hline 13 & MIS14 & 201.92 & 38.73739 & 53822.93829 & $4.0 \pm 1.0$ & 1.366 & 0.505 \\
\hline 14 & MIS9 & 217.13 & 26.95383 & 3925480.88407 & $2.9 \pm 0.8$ & 0.107 & 0.948 \\
\hline 15 & MIS16 & 256.41 & 34.62919 & 1531082.54686 & $3.3 \pm 0.9$ & 0.268 & 0.874 \\
\hline 16 & MIS8 & 300.48 & 32.58871 & 35029799.27609 & $2.9 \pm 0.8$ & 0.226 & 0.893 \\
\hline 17 & MIS17 & 314.67 & 44.20990 & 959879.03055 & $3.6 \pm 0.9$ & 0.075 & 0.963 \\
\hline 18 & MIS6 & 344.54 & 41.35598 & 8152760.21599 & $3.3 \pm 0.9$ & 0.093 & 0.955 \\
\hline 19 & MIS11 & 362.13 & 59.99479 & 475700.31977 & $4.3 \pm 1.1$ & 0.762 & 0.683 \\
\hline 19 & MIS21 & 362.13 & 59.99479 & 475700.31977 & $4.3 \pm 1.1$ & 0.762 & 0.683 \\
\hline 19 & MIS22 & 362.13 & 59.99479 & 475700.31977 & $4.3 \pm 1.1$ & 0.762 & 0.683 \\
\hline 20 & MIS5 & 414.59 & 52.44195 & 3709702.67431 & $3.6 \pm 1.0$ & 0.106 & 0.948 \\
\hline 21 & MIS25 & 416.82 & 39.57977 & $5.414953 \mathrm{E}+21$ & $2.8 \pm 0.7$ & 0.187 & 0.915 \\
\hline 22 & MIS12 & 424.41 & 39.57977 & $5.414953 \mathrm{E}+13$ & $2.9 \pm 0.8$ & 0.712 & 0.700 \\
\hline 23 & MIS24 & 628.92 & 41.49018 & $1.1956121 \mathrm{E}+30$ & $2.7 \pm 0.8$ & 0.065 & 0.971 \\
\hline
\end{tabular}

$\mathrm{E}=$ exponent

Table 2: Time-dose-mortality response $\left(\mathrm{LT}_{50}\right)$ of Metarhizium isolates to E. narcissus.

\begin{tabular}{llcccccc}
\hline Isolates & Conc. & $\mathrm{LT}_{50}$ & \multicolumn{2}{l}{ Fiducial Limits } & Slope \pm SE & $\chi^{2}$ & $\mathrm{P}$ \\
\cline { 4 - 6 } & & & Lower & Upper & & & \\
\hline MIS 1 & $1 \times 10^{4}$ & 8.1 & - & - & $7.2 \pm 3.50$ & 0.15 & 0.99 \\
& $1 \times 10^{5}$ & 7.0 & - & - & $15.7 \pm 13.90$ & 0.06 & 0.99 \\
& $1 \times 10^{6}$ & 6.7 & 5.8 & 12.5 & $5.8 \pm 1.70$ & 0.20 & 0.99 \\
MIS 2 & $1 \times 10^{7}$ & 5.9 & 5.1 & 8.0 & $4.1 \pm 0.90$ & 1.81 & 0.77 \\
& $1 \times 10^{4}$ & 8.1 & - & - & $7.2 \pm 3.50$ & 0.15 & 0.99 \\
& $1 \times 10^{5}$ & 7.0 & 6.0 & 29.8 & $7.0 \pm 2.50$ & 0.91 & 0.92 \\
& $1 \times 10^{6}$ & 6.5 & 5.6 & 11.0 & $5.3 \pm 1.40$ & 0.43 & 0.98 \\
MIS 3 & $1 \times 10^{7}$ & 5.2 & 4.6 & 6.1 & $4.6 \pm 0.90$ & 0.16 & 0.99 \\
& $1 \times 10^{4}$ & 8.1 & - & - & $7.2 \pm 3.50$ & 0.15 & 0.99 \\
& $1 \times 10^{5}$ & 7.2 & 6.1 & 72.7 & $7.1 \pm 2.70$ & 0.35 & 0.98 \\
& $1 \times 10^{6}$ & 7.1 & 5.9 & 18.8 & $5.8 \pm 1.80$ & 0.12 & 0.99 \\
MIS 4 & $1 \times 10^{7}$ & 5.8 & 5.3 & 7.2 & $7.1 \pm 1.80$ & 0.38 & 0.98 \\
& $1 \times 10^{4}$ & 9.0 & - & - & $6.6 \pm 3.50$ & 0.25 & 0.99 \\
& $1 \times 10^{5}$ & 8.1 & - & - & $7.2 \pm 3.50$ & 0.15 & 0.99 \\
& $1 \times 10^{6}$ & 7.7 & 6.2 & 64.9 & $5.5 \pm 1.80$ & 0.26 & 0.99 \\
MIS 5 & $1 \times 10^{7}$ & 6.8 & 5.6 & 12.8 & $4.5 \pm 1.20$ & 1.13 & 0.88 \\
& $1 \times 10^{4}$ & 9.0 & - & - & $6.6 \pm 3.50$ & 0.25 & 0.99 \\
& $1 \times 10^{5}$ & 8.7 & 6.5 & 36.5 & $5.2 \pm 1.90$ & 0.82 & 0.93 \\
& $1 \times 10^{6}$ & 7.5 & - & - & $14.3 \pm 10.70$ & 0.04 & 1.00 \\
MIS 6 & $1 \times 10^{7}$ & 6.5 & 5.7 & 11.0 & $6.4 \pm 1.90$ & 1.12 & 0.89 \\
& $1 \times 10^{4}$ & 8.1 & - & - & $7.2 \pm 3.50$ & 0.15 & 0.99 \\
& $1 \times 10^{5}$ & 7.6 & - & - & $7.4 \pm 3.30$ & 0.23 & 0.99 \\
& $1 \times 10^{6}$ & 7.5 & - & - & $14.3 \pm 10.70$ & 0.04 & 1.00 \\
& $1 \times 10^{7}$ & 6.5 & 5.6 & 11.0 & $5.3 \pm 1.40$ & 0.43 & 0.98
\end{tabular}


Bai et al. /Journal of Tropical Forestry and Environment Vol. 5. No 01 (2015) 47-58

\begin{tabular}{|c|c|c|c|c|c|c|c|}
\hline \multirow[t]{4}{*}{ MIS 7} & $1 \times 10^{4}$ & 7.0 & - & - & $7.4 \pm 3.30$ & 0.23 & 0.9 \\
\hline & $1 \times 10^{5}$ & 6.8 & 5.7 & 13.1 & $5.1 \pm 1.40$ & 0.48 & \\
\hline & $1 \times 10^{6}$ & 5.7 & 4.9 & 7.9 & $3.8 \pm 0.80$ & 0.46 & \\
\hline & $1 \times 10^{7}$ & 4.9 & 4.4 & 5.9 & $3.8 \pm 0.70$ & 0.90 & \\
\hline \multirow[t]{4}{*}{ MIS 8} & $1 \times 10^{4}$ & 9.0 & - & - & $6.6 \pm 3.50$ & 0.25 & \\
\hline & $1 \times 10^{5}$ & 8.1 & - & - & $6.5 \pm 2.80$ & 0.76 & \\
\hline & $1 \times 10^{6}$ & 7.0 & 6.0 & 29.8 & $7.0 \pm 2.50$ & 0.91 & \\
\hline & $1 \times 10^{7}$ & 6.2 & 5.4 & 8.8 & $5.6 \pm 1.50$ & 0.30 & \\
\hline \multirow[t]{4}{*}{ MIS 9} & $1 \times 10^{4}$ & 9.0 & - & - & $6.6 \pm 3.50$ & 0.25 & \\
\hline & $1 \times 10^{5}$ & 8.1 & - & - & $7.2 \pm 3.50$ & 0.15 & \\
\hline & $1 \times 10^{6}$ & 7.1 & 5.9 & 18.8 & $5.8 \pm 1.80$ & 0.12 & \\
\hline & $1 \times 10^{7}$ & 6.2 & 5.4 & 8.8 & $5.6 \pm 1.50$ & 0.30 & \\
\hline \multirow{4}{*}{ MIS 10} & $1 \times 10^{4}$ & 11.5 & - & - & $5.6 \pm 3.40$ & 0.66 & \\
\hline & $1 \times 10^{5}$ & 8.1 & - & - & $7.2 \pm 3.50$ & 0.15 & \\
\hline & $1 \times 10^{6}$ & 7.2 & 6.1 & 72.7 & $7.1 \pm 2.70$ & 0.35 & \\
\hline & $1 \times 10^{7}$ & 6.2 & 5.4 & 8.8 & $5.6 \pm 1.50$ & 0.30 & \\
\hline \multirow[t]{4}{*}{ MIS 11} & $1 \times 10^{4}$ & 9.0 & - & - & $6.6 \pm 3.50$ & 0.25 & \\
\hline & $1 \times 10^{5}$ & 7.6 & - & - & $7.4 \pm 3.30$ & 0.23 & \\
\hline & $1 \times 10^{6}$ & 7.5 & - & - & $14.3 \pm 10.70$ & 0.04 & \\
\hline & $1 \times 10^{7}$ & 7.0 & 6.0 & 27.3 & $7.0 \pm 2.50$ & 0.50 & \\
\hline \multirow{4}{*}{ MIS 12} & $1 \times 10^{4}$ & 9.5 & - & - & $4.6 \pm 1.70$ & 0.37 & \\
\hline & $1 \times 10^{5}$ & 9.0 & - & - & $6.6 \pm 3.50$ & 0.25 & \\
\hline & $1 \times 10^{6}$ & 7.5 & 6.2 & 45.2 & $7.0 \pm 2.80$ & 0.47 & \\
\hline & $1 \times 10^{7}$ & 6.4 & 5.6 & 10.3 & $5.2 \pm 1.40$ & 0.40 & \\
\hline \multirow[t]{4}{*}{ MIS 13} & $1 \times 10^{4}$ & 7.1 & 5.9 & 18.8 & $5.8 \pm 1.80$ & 0.12 & \\
\hline & $1 \times 10^{5}$ & 6.8 & 5.7 & 13.1 & $5.1 \pm 1.40$ & 0.48 & \\
\hline & $1 \times 10^{6}$ & 6.1 & 5.3 & 8.6 & $4.6 \pm 1.10$ & 0.47 & \\
\hline & $1 \times 10^{7}$ & 5.4 & 4.8 & 6.6 & $4.7 \pm 1.00$ & 0.06 & \\
\hline \multirow[t]{4}{*}{ MIS 14} & $1 \times 10^{4}$ & 9.0 & - & - & $6.6 \pm 3.50$ & 0.25 & \\
\hline & $1 \times 10^{5}$ & 8.1 & - & - & $7.2 \pm 3.50$ & 0.15 & \\
\hline & $1 \times 10^{6}$ & 7.2 & 6.1 & 72.7 & $7.1 \pm 2.70$ & 0.35 & \\
\hline & $1 \times 10^{7}$ & 6.7 & 5.6 & 12.3 & $4.2 \pm 1.00$ & 0.27 & \\
\hline \multirow[t]{4}{*}{ MIS 15} & $1 \times 10^{4}$ & 9.0 & - & - & $6.6 \pm 3.50$ & 0.25 & \\
\hline & $1 \times 10^{5}$ & 8.2 & 6.3 & 11.1 & $5.7 \pm 2.30$ & 1.85 & \\
\hline & $1 \times 10^{6}$ & 7.7 & 6.2 & 64.9 & $5.5 \pm 1.80$ & 0.26 & \\
\hline & $1 \times 10^{7}$ & 6.5 & 5.5 & 10.6 & $4.3 \pm 1.00$ & 0.41 & \\
\hline \multirow[t]{4}{*}{ MIS 16} & $1 \times 10^{4}$ & 8.1 & - & - & $7.2 \pm 3.50$ & 0.15 & \\
\hline & $1 \times 10^{5}$ & 7.5 & - & - & $14.3 \pm 10.70$ & 0.04 & 1. \\
\hline & $1 \times 10^{6}$ & 7.2 & 6.1 & 72.7 & $7.1 \pm 2.70$ & 0.35 & 0. \\
\hline & $1 \times 10^{7}$ & 6.5 & 5.5 & 10.6 & $4.3 \pm 1.00$ & 0.41 & 0. \\
\hline \multirow[t]{4}{*}{ MIS 17} & $1 \times 10^{4}$ & 9.0 & - & - & $6.6 \pm 3.50$ & 0.25 & 0. \\
\hline & $1 \times 10^{5}$ & 7.5 & - & - & $14.3 \pm 10.70$ & 0.04 & 1. \\
\hline & $1 \times 10^{6}$ & 7.2 & 6.1 & 72.7 & $7.1 \pm 2.70$ & 0.35 & \\
\hline & $1 \times 10^{7}$ & 6.5 & 5.6 & 11.0 & $5.3 \pm 1.40$ & 0.43 & \\
\hline \multirow[t]{4}{*}{ MIS 18} & $1 \times 10^{4}$ & 9.0 & - & - & $6.6 \pm 3.50$ & 0.25 & \\
\hline & $1 \times 10^{5}$ & 7.5 & 6.2 & 45.2 & $7.0 \pm 2.80$ & 0.47 & \\
\hline & $1 \times 10^{6}$ & 7.1 & 5.9 & 18.8 & $5.8 \pm 1.80$ & 0.12 & \\
\hline & $1 \times 10^{7}$ & 6.0 & 5.3 & 8.4 & $4.8 \pm 1.20$ & 1.02 & 0. \\
\hline \multirow{4}{*}{ MIS 19} & $1 \times 10^{4}$ & 8.1 & - & - & $7.2 \pm 3.50$ & 0.15 & \\
\hline & $1 \times 10^{5}$ & 8.1 & 6.3 & 167.1 & $5.0 \pm 1.70$ & 0.46 & 0. \\
\hline & $1 \times 10^{6}$ & 6.7 & 5.8 & 12.5 & $5.8 \pm 1.70$ & 0.20 & 0. \\
\hline & $1 \times 10^{7}$ & 5.9 & 5.3 & 7.4 & $6.2 \pm 1.50$ & 0.30 & 0. \\
\hline \multirow[t]{4}{*}{ MIS 20} & $1 \times 10^{4}$ & 8.1 & - & - & $7.2 \pm 3.50$ & 0.15 & \\
\hline & $1 \times 10^{5}$ & 8.0 & 6.3 & 167.1 & $5.0 \pm 1.70$ & 0.46 & \\
\hline & $1 \times 10^{6}$ & 6.2 & 5.4 & 8.8 & $5.6 \pm 1.50$ & 0.30 & \\
\hline & $1 \times 10^{7}$ & 5.7 & 5.0 & 7.3 & $4.7 \pm 1.00$ & 0.13 & \\
\hline
\end{tabular}




\begin{tabular}{cccccccc} 
MIS 21 & $1 \times 10^{4}$ & - & - & - & - & - & - \\
& $1 \times 10^{5}$ & 9.0 & - & - & $6.6 \pm 3.50$ & 0.25 & 0.99 \\
& $1 \times 10^{6}$ & 7.5 & 6.2 & 45.2 & $7.0 \pm 2.80$ & 0.47 & 0.97 \\
& $1 \times 10^{7}$ & 6.9 & 5.8 & 14.6 & $5.2 \pm 1.50$ & 0.77 & 0.94 \\
MIS 22 & $1 \times 10^{4}$ & - & - & - & - & - & - \\
& $1 \times 10^{5}$ & 7.5 & 6.1 & 37.0 & $5.3 \pm 1.70$ & 0.22 & 0.99 \\
& $1 \times 10^{6}$ & 7.0 & - & - & $15.7 \pm 13.90$ & 0.06 & 0.99 \\
& $1 \times 10^{7}$ & 6.5 & 5.5 & 10.6 & $4.3 \pm 1.00$ & 0.41 & 0.98 \\
MIS 23 & $1 \times 10^{4}$ & - & - & - & - & - & - \\
& $1 \times 10^{5}$ & 8.1 & - & - & $7.2 \pm 3.50$ & 0.15 & 0.99 \\
& $1 \times 10^{6}$ & 7.2 & 6.0 & 24.0 & $5.9 \pm 1.90$ & 0.38 & 0.98 \\
\multirow{2}{*}{ MIS 24 } & $1 \times 10^{7}$ & 6.2 & 5.4 & 8.8 & $5.6 \pm 1.50$ & 0.30 & 0.99 \\
& $1 \times 10^{4}$ & 9.3 & - & - & $5.6 \pm 2.60$ & 1.26 & 0.86 \\
& $1 \times 10^{5}$ & 7.5 & - & - & $14.3 \pm 10.70$ & 0.04 & 1.00 \\
& $1 \times 10^{6}$ & 7.5 & 6.1 & 37.0 & $5.3 \pm 1.70$ & 0.22 & 0.99 \\
\multirow{2}{*}{ MIS 25 } & $1 \times 10^{7}$ & 6.4 & 5.4 & 10.2 & $4.2 \pm 1.00$ & 0.25 & 0.99 \\
& $1 \times 10^{4}$ & - & - & - & - & - & - \\
& $1 \times 10^{5}$ & 8.1 & - & - & $7.2 \pm 3.50$ & 0.15 & 0.99 \\
& $1 \times 10^{6}$ & 7.1 & 5.9 & 18.8 & $5.8 \pm 1.80$ & 0.12 & 0.99 \\
& $1 \times 10^{7}$ & 5.9 & 5.1 & 8.0 & $4.4 \pm 1.00$ & 0.13 & 0.99 \\
\hline
\end{tabular}

Significant difference in mortality was observed between the seven combinations tested. Increased mortality was recorded with the combination treatments compared to individual treatments. Evaluation of various formulations revealed the combination MIS7+MIS13+0.5\% P. pinnata seed oil to be superior over the other treatments which resulted in 76.30\% mortality. MIS7+MIS13 showed $74.82 \%$ mortality (Table 3). About 6-18\% increase in mortality was reported with formulations when used in combinations.

Synergistic effects of different isolates of a single fungal species, especially Metarhizium on insect mortality have not been reported. However, the effect of interaction of B. bassiana, M. anisopilae and L. lecanii was tested by Mahmoud (2009). These authors analysed the synergistic and antagonistic interactions based on a comparison of mortality of adults by these fungi when used alone and in combination.

The combination of $B$. bassiana $M$. anisopilae gave a synergistic response while the combination of B. Bassiana + L. lecanii and $M$. Anisopliae $+L$. lecanii gave an antagonistic response. The possibility of using mixtures of different species of entomopathogenic fungi for the control of western flower thrips, Frankliniella occidentalis was reported by Gouli et al. (2008).

Interaction between the fungi B. bassiana, M. anisopilae and the diatomaceous earth dusts with negligible effect on the viability of conidia was observed by Batta (2008). Oil based formulations have shown better tolerance to temperature and desiccation, enhanced speed of germination of conidia, improved environmental stability and overall performance as fungal biopesticides (Jackson et al., 2010). In the present study, usage of $P$. pinnata seed oil would have provided these advantages in addition to its insecticidal activity. 
Table 3: Evaluation of different combinations of $M$. anisopliae isolates and $P$. pinnata seed oil against E. narcissus.

\begin{tabular}{lc}
\hline Treatments & $\begin{array}{c}\text { Mean mortality of } E . \\
\text { narcissus }\end{array}$ \\
\hline MIS7 & 70.33 \\
MIS13 & 64.80 \\
0.5\% Pongam oil & 58.86 \\
MIS7 + MIS13 & 74.82 \\
MIS7+0.5\% Pongam oil & 73.18 \\
MIS13+0.5\% Pongam oil & 68.25 \\
MIS7 + MIS13+0.5\% Pongam oil & 76.30 \\
SED & 0.43 \\
CD $(.05)$ & 0.87 \\
CD $(.01)$ & 1.17 \\
\hline SED
\end{tabular}

$\mathrm{SED}=$ standard error of the difference between means; $\mathrm{CD}=$ critical difference

\subsection{Field Trial}

Mean number of pest larvae in the experimental plots prior to treatment ranged from 13.07 to 14.13 per plant in Location I and 13.99 to 14.27 in Location II. After seven days of treatment, the treatment T2 (MIS7+MIS13+0.5\% P. pinnata seed oil) proved to be superior over other treatments as indicated by the high reduction of infestation in both locations. The treatment $\mathrm{T} 2$ recorded 5.01 larvae per plant in location I and 6.59 larvae per plant in location II which differed significantly from the treatment T1. Mean number of 14.12 larvae/plant in location I and 15.03 larvae/plant in location II were recorded in Treatment T3 (untreated control). Observations recorded after fifteen days of imposition of treatments revealed significant differences between the treatments. Treatment T2 recorded a mean number of 6.13 larvae/plant in location I while T1 recorded 5.57 larvae. In Location II also, T2 was found promising with 5.43 larvae per plant. The control (T3) recorded 14.38 larvae/plant and 15.91 larvae/plant in location I and II respectively. Overall reduction of infestation for different treatments was calculated by combining the data from both the locations. The treatment T2 recorded a mean number of 5.79 larvae/plant which works out to $60.53 \%$ reduction of infestation. $53.76 \%$ reduction of infestation was observed in T1 (Table 4). Augmenting the formulation with $P$. pinnata seed oil increased the overall reduction in infestation of E. narcissus by about $7 \%$. There has been no field trial studies reported using Metarhizium isolates against E. narcissus.

In one reported case of natural infection by an entomopathogenic fungus $P$. farinosus, $40 \%$ pupal mortality of E. narcissus was reported by Mohanan and Varma (1988) indicating the prospects of using entomopathogenic fungi for biological control of this pest. Control of E. narcissusin nurseries and young plantations using insecticides, Fenvalerate and Quinalphos was reported by Varma (1986) and Roonwal (1990). The observations from this study suggest the prospects of using the entomopathogenic fungus, $M$. anisopliae for the control of E. narcissus. The death of the host insect results from the invasion and colonization of the host body by the fungus and/or due to the toxins produced by the fungus. Many chemical pesticides are now being phased out because of their wider impact on ecosystems and this study reaffirms the fact that entomopathogenic fungi can be an important alternative to chemicals for pest management. 
Table 4: Reduction of E. narcissus infestation on A. excelsa.

\begin{tabular}{|c|c|c|c|c|c|c|c|c|c|c|c|}
\hline \multirow{3}{*}{ Treatments } & \multicolumn{11}{|c|}{ Average number of larvae/Plant } \\
\hline & \multicolumn{4}{|c|}{ Location-I } & \multicolumn{4}{|c|}{ Location-II } & \multicolumn{2}{|c|}{$\begin{array}{c}\text { Location } \\
\text { Mean }\end{array}$} & \multirow[t]{2}{*}{$\begin{array}{l}\text { R I } \\
(\%)\end{array}$} \\
\hline & $\begin{array}{c}1 \\
\text { DBT }\end{array}$ & $\begin{array}{c}7 \\
\text { DAT }\end{array}$ & $\begin{array}{c}15 \\
\text { DAT }\end{array}$ & Mean & $\begin{array}{c}1 \\
\text { DBT }\end{array}$ & $\begin{array}{c}7 \\
\text { DAT }\end{array}$ & $\begin{array}{c}15 \\
\text { DAT }\end{array}$ & Mean & DBT & DAT & \\
\hline T1 & 13.07 & 6.87 & 5.57 & 6.22 & 13.99 & 7.38 & 6.42 & 6.90 & 13.53 & 6.56 & 53.76 \\
\hline $\mathbf{T 2}$ & 13.86 & 5.01 & 6.13 & 5.57 & 14.18 & 6.59 & 5.43 & 6.01 & 14.02 & 5.79 & 60.53 \\
\hline \multirow[t]{9}{*}{ T3 } & 14.13 & 14.12 & 14.38 & 14.25 & 14.27 & 15.03 & 15.94 & 15.47 & 14.20 & 14.86 & \\
\hline & & & & SED & \multicolumn{2}{|c|}{ CD (0.05) } & CD (0.01) & & & & \\
\hline & & \multirow{2}{*}{\multicolumn{2}{|c|}{$\begin{array}{l}\text { l-location } \\
\text { t-treatment }\end{array}$}} & 0.02270 & \multicolumn{2}{|c|}{0.04615} & 0.06193 & & & & \\
\hline & & & & 0.02780 & \multicolumn{2}{|c|}{0.05652} & 0.07585 & & & & \\
\hline & & \multicolumn{2}{|c|}{$\begin{array}{c}\text { t-treatment } \\
\text { d-days }\end{array}$} & 0.02780 & \multicolumn{2}{|c|}{0.05652} & 0.07585 & & & & \\
\hline & & \multicolumn{2}{|c|}{$1 \mathrm{t}$} & 0.03931 & \multicolumn{2}{|c|}{0.07993} & 0.10727 & & & & \\
\hline & & \multicolumn{2}{|c|}{$\mathrm{t} d$} & 0.04815 & \multicolumn{2}{|c|}{0.09790} & 0.13137 & & & & \\
\hline & & \multicolumn{2}{|c|}{$1 \mathrm{~d}$} & 0.03931 & \multicolumn{2}{|c|}{0.07993} & 0.10727 & & & & \\
\hline & & & 0.06809 & & 0.18579 & & & & \\
\hline
\end{tabular}

$\mathrm{DBT}=$ Day before treatment; DAT $=$ Days after treatment; RI: Reduction of infestation,

T1- MIS7+MIS13; T2- MIS7+MIS13+pongam oil (0.5\%); T3-0.08\% tween 80 (control)

The key question that arises with the use of fungi in field is the long term storage and viability as the conservation of viability and efficacy after long term storage and field persistence are very important for the successful application of the formulation under field conditions. Further studies to ascertain the efficacy of the isolates in the field even after storage and methods to enhance the field persistence will pave way for successful application of these formulations as a biocontrol agent for Ailanthus defoliator, E. narcissus.

\section{Acknowledgement}

The authors acknowledge the Department of Biotechnology, New Delhi for providing financial support to carry out this work. Authors also acknowledge the Director, ATREE and IWST, Bangalore for providing facilities to undertake the study. The permission granted by the PCCF Karnataka and PCCF Kerala to undertake survey in the states is also acknowledged.

\section{References}

Batta, Y.A., 2008. Control of main stored grain insects with new formulations of entomopathogenic fungi in diatomaceous earth dusts. International Journal of Food Engineering, 4(1): 56-64.

Bhasin, G.D. and Roonwal, M.L. 1954. A list of insect pests of forest plants in India and adjacent countries. Part 2. Lists of insect pests of plant genera A (Aberia to Azima). Indian For. Bull, 171(1): 93.

Chatterjee, P.N. and Sen Sarma, P.K. 1968. Important current problems of forest entomology in India. Indian Forester, 94: 112-117.

Chatterjee, P.N., Singh, P. and Misra, R.N. 1969. Studies on the biology, ecology, life cycle and parasite complex of Ailanthus defoliator, Eligma narcissus Cramer (Noctuidae: Lepidoptera), together with morphology of adult and immature stages. Indian Forester, 95: 541-550.

Cunningham, J.C. and Frankenhuyzen,V.K. 1991. Microbial insecticides in forestry. The Forestry Chronicle, 67(5): 473-480. 
David, B.V. and Ananthakrishnan T.N. 2004. General and Applied Entomology. Tata Mc Graw-Hill publishing company Limited, New Delhi.

Finney, D.J. 1971. Probit Analysis (ed.3). Cambridge University Press, Cambridge, UK.

Gouli, S., Gouli, V., Skinner, M., Parker, B., Marcelino, J. and Shternshis, M. 2008. Mortality of western flower thrips, Frankliniella occidentalis, under influence of single and mixed fungal inoculations. Journal of Agricultural Technology,4(2): 37-47.

Henderson, C.F. and Tilton, E.W. 1955. Tests with acaricides against the brow wheat mite. Journal of Economic Entomology, 48: 157-161.

Jackson, M.A., Dunlap, C.A. and Jaronski, S.T. 2010. Ecological considerations in producing and formulating fungal entomopathogens for use in insect biocontrol. Biocontrol, 55: 129-145.

Jha, L.K. and Sen-Sarma, P.K. 2008. Forest Entomology. APH Publishing Corporation, New Delhi.

Joseph, T.M. 2000. Antifeedant and growth inhibitory effects of neem seed kernel extract on Ailanthus defoliator, Eligma narcissus indica Roth. (Lepidoptera: Noctuidae). Entomon, 25(1): 67-72.

Kabuluk, T., Goettel, M., Vernon, B. and Noronha, C. 2001. Evaluation of Metarhizium anisopliae as a biological Control for Wireworms. Pacific Agri-Food Research Centre (Agassiz) contribution no. 165.

Lomer, C.J., Bateman, R.P., Johnson, D.L., Langewald, J. and Thomas, M.B. 2001. Biological control of locusts and grasshoppers. Annual Review of Entomology, 46: 667-702.

Mahmoud,M.F. 2009. Pathogenicity of Three Commercial Products of Entomopathogenic Fungi, Beauveria bassiana, Metarhizum anisopilae and Lecanicillium lecanii against Adults of Olive Fly, Bactrocera oleae (Gmelin) (Diptera: Tephritidae) in the laboratory. Plant Protection Science, 45(3): 98-102.

Mohammed Ali, M.I. and Varma, R.V. 1992. Fungal pathogens of Eligma narcissus indica with special reference to Paecilomyces sp. Phytophaga, 4: 101-109.

Mohammed Ali, M.I., Varma, R.V. and Sudheendrakumar, V.V. 1991. Evaluation of microbial pathogens for biocontrol against insect pests of Teak and Ailanthus. KFRI research report No.73. KFRI, Peechi.

Mohanan, C. and Varma, R.V.1988.Paecilomyces farinosus, a potential biocontrol agent of some lepidopterous tree pests in India. Transactions of the British Mycological Society. 90(1): 119122.

Nair, K.S. S.2007. Tropical forest insect pests: Ecology, impact, and management. Cambridge University Press, Cambridge, UK.

Roonwal, M.L. 1990. Field-ecological observations on the Ailanthus excelsa defoliator, Eligma narcissus indica (Lepidoptera, Noctuidae), in Peninsular India. Indian Journal of Forestry. 13(2): 81-84.

Roonwal, M.L. 1982. Illustration of the life history stages of the Ailanthus defoliator Eligma narcissus indica (Lepidoptera: Noctuidae). Indian Journal of forestry. 54: 270-276.

Saxena, H. 2008. Microbial management of crop pest. Journal of Biopesticides, 1(1): 32-37.

Senapati, S.K.1999. Conservation and Utilisation of Natural Enemies of Crop Pests and Diseases under Terai Region of West Bengal. Research report submitted to Bidhan Chandra Krishi Viswavidyalaya, North Bengal Campus, West Bengal.

Tewari, D.N.1992. Tropical Forestry in India. International Book Distributors, Dehra Dun.

Varma, R.V. 1986. Seasonal incidence and possible control of important pasts in plantations of Ailanthus triphysa. KFRI Research Report No.39.

Varma, R.V. 1991. Spatial and temporal distribution of Ailanthus pests, Eligma narcissus and Atteva fabriciella. KFRI Research report No. 78. 
Varma, R.V. and Mohammed Ali, M.I. 1986. Bacillus firmus as a new insect pathogen on a lepidopteran pest of Ailanthus triphysa. Journal of Invertebrate Pathology. 47: 379-380.

Weinzierl, R. and Henn, T. 1991. Alternatives in insect management: biological and biorational approaches. North Central Regional extension Publication, Cooperative Extension Service, Univ. of Illinois at Urbana-Champaign.

Weinzierl, R., Henn, T., Koehler, P. G. and Tucker, C. L. 2005.Microbial Insecticides. Series ENY-275 (IN081), Entomology and Nematology Department. IFAS Extension, University of Florida.

Zayed, A. 2003. Pathogenecity of two Beauveria bassiana indigenous isolates towards the greater wax moth Galleria mellonella larvae in Egypt. Efflatounia. 3: 10-14.

Zimmermann, G. 1986. The Galleria bait method for detection of entomopathogenic fungi in soil. Journal of Applied Entomology. 102: 213-215. 